\title{
Neutral Aminyl Radicals Derived from Azoimidazolium Dyes
}

\author{
Léonard Y. M. Eymann, ${ }^{\dagger}$ Alexander G. Tskhovrebov, ${ }^{\dagger}$ Andrzej Sienkiewicz, ${ }^{\ddagger}$ José L. Bila, ${ }^{\dagger}$ Ivica Živ- \\ ković, ${ }^{\ddagger}$ Henrik M. Rønnow, ${ }^{\ddagger}$ Matthew D. Wodrich, ${ }^{\dagger}$ Laurent Vannay, ${ }^{\dagger}$ Clémence Corminboeuf, ${ }^{\dagger}$ Philip \\ Pattison, ${ }^{\ddagger}{ }^{\S}$ Euro Solari, ${ }^{\dagger}$ Rosario Scopelliti, ${ }^{\dagger}$ Kay Severin* ${ }^{\dagger} \dagger$ \\ ${ }^{\dagger}$ Institut des Sciences et Ingénierie Chimiques, École Polytechnique Fédérale de Lausanne (EPFL), CH-1015 Lausanne, \\ Switzerland \\ ${ }^{\ddagger}$ Institute of Physics, École Polytechnique Fédérale de Lausanne (EPFL), CH-1015 Lausanne, Switzerland \\ $\S$ Swiss-Norwegian Beamline, ESRF, Grenoble, France
}

Supporting Information Placeholder

\begin{abstract}
The synthesis and the characterization of a new class of neutral aminyl radicals is reported. Monoradicals were obtained by reduction of azoimidazolium dyes with potassium. Structural, spectroscopic, and computational data suggest that the spin density is centered on one of the nitrogen atoms of the former azo group. The reduction of a dimeric dye with an octamethylbiphenylene bridge between the azo groups resulted in the formation a biradical with largely independent unpaired electrons. Both, the monoradicals and the biradical were found to display high stability in solution as well as in the solid state.
\end{abstract}

Cationic azo dyes containing imidazolium groups are produced industrially and used for a variety of applications including the dying of natural and synthetic fibers. ${ }^{1}$ Despite the technical importance of azoimidazolium dyes, there are relatively few reports about these compounds in the scientific literature. This is particularly true for dyes with 1,3-diarylimidazolium groups, which have mainly been described in the patent literature. ${ }^{2}$ We have recently reported a new procedure for the preparation of azoimidazolium dyes. ${ }^{3}$ Notably, this procedure allows accessing dyes with 1,3-diarylimidazolium groups in a straightforward manner. While studying the properties of these $\mathrm{N}$-aryl-substituted dyes, we found that they can be converted into stable neutral radicals. Details about these findings are reported below.

Azoimidazolium dyes with methyl substituents attached to the heterocycle are known to undergo a photochemically-induced trans-cis isomerization (Scheme 1a). ${ }^{4}$ For dyes with N-aryl substituents, such an isomerization seemed difficult due to strong steric congestion of the hypothetical cis form. Nevertheless, we decided to study the photochemical behavior of dye 1, having two sterically demanding mesityl groups attached to the imidazolium group. Upon broadband UV irradiation of a solution of 1 in THF- $d_{8}$, we observed a surprising result: the ${ }^{1} \mathrm{H}$ NMR signals of the cation, but not of the $\mathrm{BPh}_{4}^{-}$anion, were no longer observable (Scheme 1b).

The formation of a paramagnetic species seemed to be a likely explanation for the vanishing NMR signals. Therefore, we examined an irradiated THF solution of 1 by ESR spectroscopy. The spectrum showed a signal with a complex hyperfine splitting pattern, in line with the formation of a nitrogen-centered organic radical (for details see SI).
Scheme 1. Photochemical behavior of azoimidazolium dyes.

a

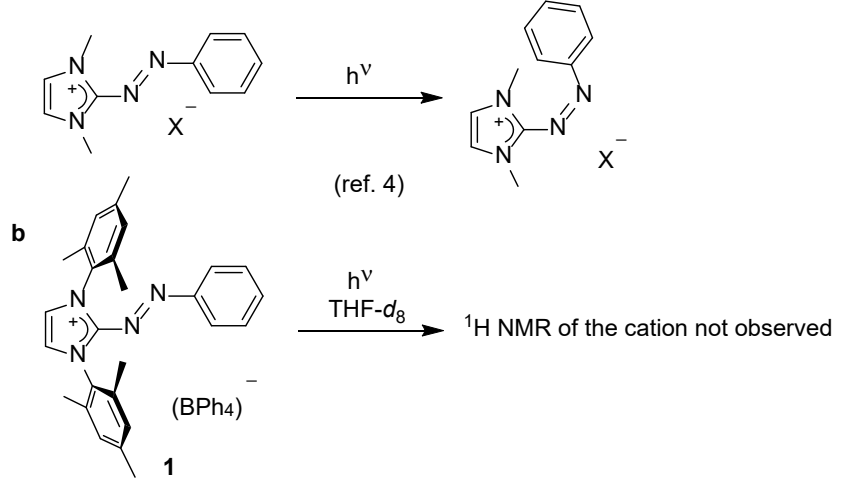

In order to understand the redox behavior of dye 1, we performed cyclic voltammetry studies using acetonitrile as solvent. A reversible one-electron reduction at $E^{0^{\prime}}=-0.89 \mathrm{~V}\left(\mathrm{vs} . \mathrm{Fc} / \mathrm{Fc}^{+}\right)$was observed. This result prompted us to attempt the reduction of $\mathbf{1}$ on a preparative scale. When a THF solution of dye 1 was mixed with one equivalent of potassium, a deepening of the color from orangered to purple was observed. Work-up allowed the isolation of the neutral radical 4 in $69 \%$ yield (Scheme 2 ). The reversibility of the redox behavior of $\mathbf{1}$ was evidenced by the fact that $\mathbf{4}$ could oxidized back to its cationic form using $\mathrm{I}_{2}$.

The ESR spectrum (THF, RT) of the isolated compound $\mathbf{4}$ was very similar to what was observed for the solution of dye $\mathbf{1}$ after irradiation (see SI, Figure S15). Quantitative ESR measurements showed that only a small fraction of 1 was converted into $\mathbf{4}$ upon irradiation $(\sim 5 \%)$. In line with this result, we found that the addition of 0.05 equivalents of 4 to a solution of $1(20 \mathrm{mM})$ in THF- $d 8$ led to the disappearance of the NMR signals of the cation of $\mathbf{1}$. This observation points to the formation of dynamic aggregates between radical $\mathbf{4}$ and the cation of $1 .^{5}$

A remarkable feature of radical 4 is its stability. At room temperature, a $20 \mathrm{mM}$ solution of $\mathbf{4}$ in degassed toluene was stable for several days. Upon exposure to air, relatively slow decomposition was observed $\left(t_{1 / 2} \sim 65 \mathrm{~h}\right)$. 
Scheme 2. Synthesis of the neutral radicals 4-6 by reduction of azoimidazolium dyes.

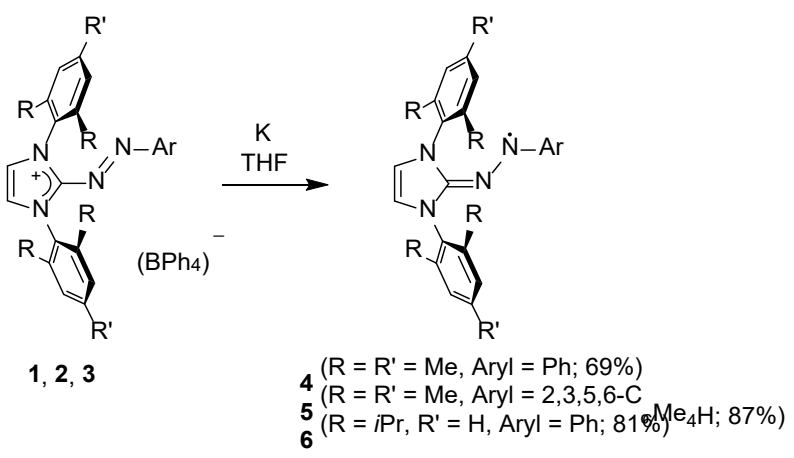

To explore structural variations, we examined the reduction of the azo dyes $\mathbf{2}$ and $\mathbf{3}$, which show different aryl substituents (Scheme 2). As in the case of $\mathbf{1}$, these reactions led to the formation of neutral radicals in good yields (5 and $\mathbf{6})$. Attempts to reduce dyes with $\mathrm{N}$-methyl or $\mathrm{N}-i$-propyl substituents were not successful: a mixture of products was observed, and the isolation of a neutral radical was not accomplished. Apparently, the presence of $\mathrm{N}$-aryl substituents is an important factor for achieving a clean reduction.

Profiting from the good stability of the radicals, single crystals of 4 and 5 were grown and analyzed by X-ray crystallography. For comparison, we have also examined the solid state structure of the starting material 1' $\left(\mathrm{BF}_{4}^{-}\right.$instead of $\left.\mathrm{BPh}_{4}^{-}\right)$. A graphic representation of the structure of $\mathbf{4}$ is shown in Figure 1 (only one of the two independent molecules in the unit cell is shown), and more details about $\mathbf{1}$ ' and $\mathbf{5}$ are provided in the supporting information.
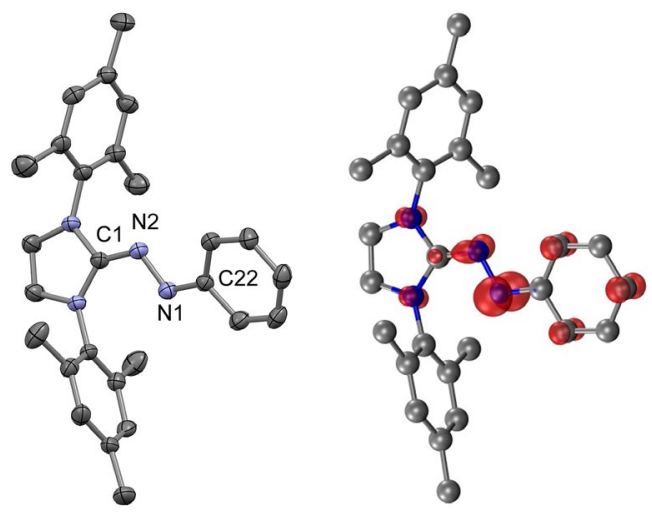

Figure 1. Graphic representation of the structure of $\mathbf{4}$ in the crystal (left, the ellipsoids are at $50 \%$ probablility), and isosurface $(0.01$ isovalue) of the spin density computed at the UTPSS/cc-pVDZ level (right). Selected bond lengths: C1-N2 : 1.316(3) and 1.364(4) $\AA ̊$, N2-N1: 1.361(3) and 1.322(3) $\AA$, N1-C22: 1.380(3) and $1.409(4) \AA$.

Comparing the average bond lengths found for the radicals $\mathbf{4}$ and $\mathbf{5}$ with those observed for the cation of 1', one can observe a lengthening of the N1-N2 bond $\left(\Delta(\mathrm{N}-\mathrm{N})_{\mathrm{av} .}=0.06 \AA\right)$ and a shortening of the $\mathrm{N} 2-\mathrm{C} 1$ bond $\left(\Delta(\mathrm{N}-\mathrm{C})_{\mathrm{av}} .=0.08 \AA\right)$ upon reduction. These changes are in line with the assumption that the spin density is centered on the nitrogen atom next to the arene ring.

The electronic structure of $\mathbf{4}$ was examined in more detail by computational chemistry. The spin densities were computed at the unrestricted TPSS/cc-pVDZ level on TPSS-D3/cc-pVDZ optimized geometries starting from the structural parameter determined by X-ray crystallography. The charge-density difference between the $\alpha$ - and the $\beta$ - spin states is graphically depicted in Figure 1 . Overall, $50 \%$ of the spin density is located on the $\mathrm{N}_{2}$ group, with the largest value $(41.5 \%)$ found for nitrogen atom N1. The compounds 4-6 can thus be described as aminyl radicals with aryl and imidazolin-2-iminato substituents. It is worth noting that closely related imidazolidin-2-iminato groups have previously been used to stabilize phosphinyl radicals. ${ }^{6}$

Diradicals bridged by polycyclic aromatic hydrocarbons have received considerable attention, both from an experimental as well as theoretical point of view. ${ }^{7}$ The biphenylene-bridged $\mathrm{Ph}_{2} \mathrm{C}-\left(\mathrm{C}_{6} \mathrm{H}_{4}\right)_{2}$ $\mathrm{CPh}_{2}$, commonly referred to as 'Tschitschibabin's hydrocarbon', has been subject to several studies, ${ }^{8,9}$ and first examples of isolelectronic nitrogen analogues of the general formula $\left[\mathrm{R}_{2} \mathrm{~N}-\left(\mathrm{C}_{6} \mathrm{H}_{2} \mathrm{R}_{2}\right)_{2}-\right.$ $\left.\mathrm{NR}_{2}\right]^{2+}$ have recently been reported..$^{10}$ Depending on the substituents R, these compounds can have substantial diradical character.

The nitrogen-based diradicaloids mentioned above are dications, and most of them display high reactivity. Our results suggested that it might be possible to prepare neutral analogues, given that one could access azoimidazolium dyes with a bridging biphenylene group.

Scheme 3. Synthesis of the diradical 8.

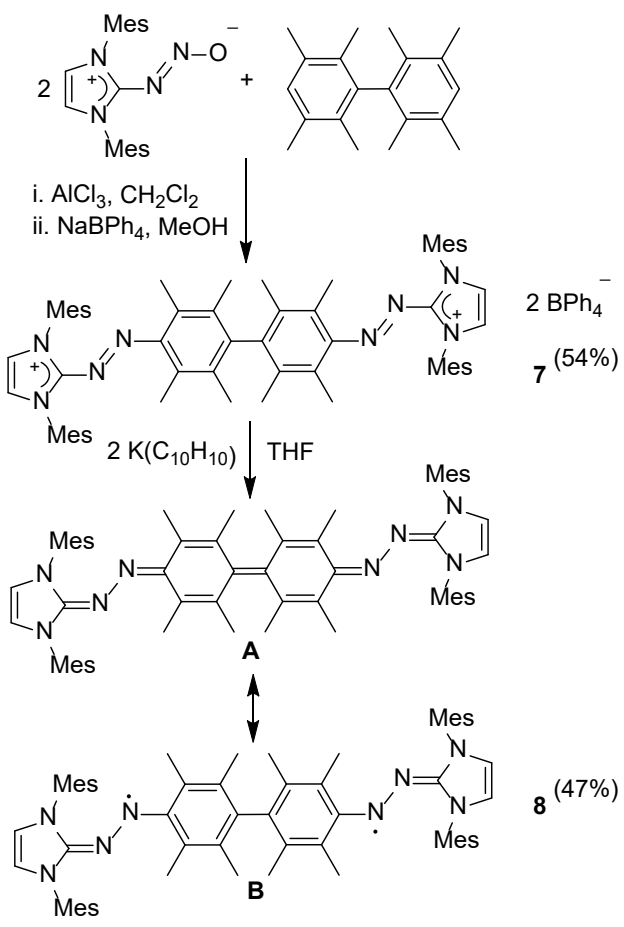

Azoimidazolium dyes can be obtained by $\mathrm{AlCl}_{3}$-induced coupling of imidazolium diazotates with the corresponding arene. ${ }^{3,11}$ By using 2,2',3,3',5,5',6,6'-octamethyl-1,1'-biphenyl as aromatic coupling partner, we were able to obtain the dicationic dye 7 in good yield (Scheme 3). Octamethylated biphenyl was used on purpose for this reaction because the substrate features only two aromatic $\mathrm{CH}$ groups. It is therefore not possible to form regioisomers during the two-fold azo-coupling reaction. Furthermore, steric interaction between the methyl groups will favor a non-planar arrangement of the two aryl rings. Such conformation is expected to reduce the electronic communication via the biphenylene bridge. ${ }^{12}$

First, we examined the redox behavior of 7 by cyclic voltammetry. One reversible reduction at $E^{0^{\prime}}=-1.04 \mathrm{~V}\left(\mathrm{vs}\right.$. Fc/Fc ${ }^{+}$) was observed. The fact that we did not observe a step-wise reduction was 
a first indication that the two azoimidazolium groups are electronically largely decoupled. In line with this assumption was the fact that reduction potential of 7 was very similar to that of the monomeric analogue $\mathbf{5}\left(E^{0}=-0.99 \mathrm{~V}\right)$.

Next, we carried out the reduction of 7 on a preparative scale using a solution of potassium naphthalenide in THF. After work-up, we were able to isolate the neutral compound 8 in $47 \%$ yield (Scheme 3).

A priori, the electronic structure of $\mathbf{8}$ can be described by two resonance forms: a 'quinoidal' closed-shell singlet (A), or an openshell diradical (B), which could either have a singlet or a triplet ground state (Scheme 3). In order to evaluate the contributions of these electronic structures, we have analyzed the dimer 8 experimentally and with DFT calculations.

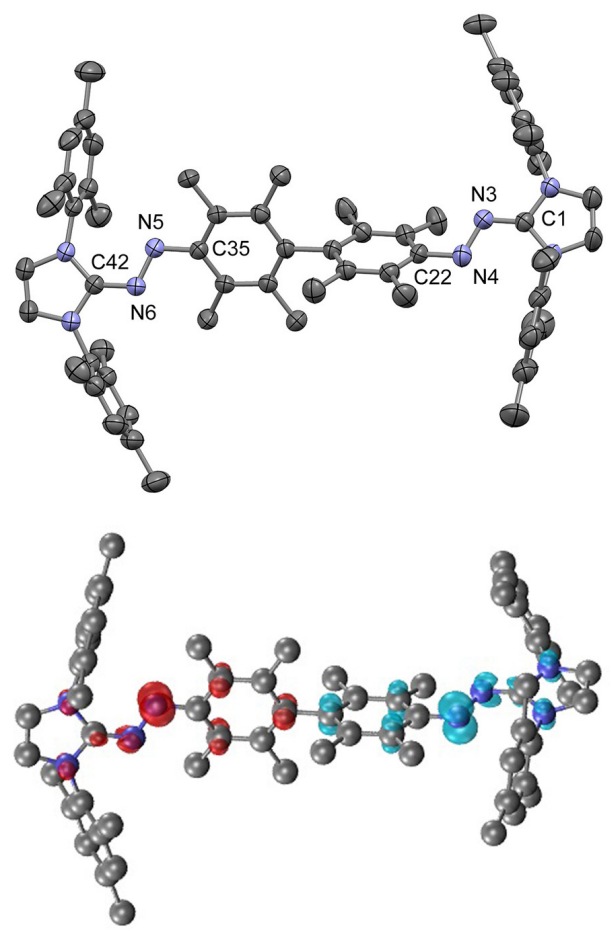

Figure 2. Molecular structure of $\mathbf{8}$ in the solid state as determined by single crystal X-ray diffraction (top; the ellipsoids are at $50 \%$ probablility), and isosurface ( \pm 0.01 isovalue) of the charge-density difference between the $\alpha$ - and $\beta$ - spin states of the open-shell singlet computed at the UTPSS/cc-pVDZ level, (bottom). Selected bond lengths: C1-N3: 1.298(4) Å, C42-N6: 1.315(6) A, N3-N4 :

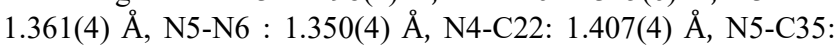
$1.393(4) \AA$

Structural data are of key importance to assess the electronic situation in conjugated diradicaloids. We therefore analyzed $\mathbf{8}$ and its precursor 7 by single crystal X-ray analysis. A graphic representation of the structure of $\mathbf{8}$ is depicted in Figure 2, and details about 7 are given in the supporting information. For the diaction 7 as well as for its reduced form $\mathbf{8}$, the two central $\mathrm{C}_{6} \mathrm{Me}_{4}$ rings are nearly orthogonal to each other $\left(7: \alpha=81^{\circ}, \mathbf{8 :} \alpha=87^{\circ}\right)$. As it was observed for the monomeric dyes, the reduction of 7 was found to lead to a lengthening of the N-N bond (7, N3-N4 : 1.244(12) $\AA, 8$, N3-N4 : 1.361(4) $\AA$, N5-N6 : 1.350(4) $\AA$ ) and a shortening of the N-C bond (7, N3-C1 : 1.494(10) Å, 8, N3-C1: 1.298(4) Å, N6-C42: 1.315(6) $\AA$ ). The $\mathrm{C}-\mathrm{C}$ bond distances within the $\mathrm{C}_{6} \mathrm{Me}_{4}$ rings of 8 alternate, but the average bond length alternation (BLA) of $0.018 \AA$ is significantly smaller than what is expected for a quinoidal systems
(BLA $>0.10 \AA) .{ }^{13}$ The bond distance between the two central $\mathrm{C}_{6} \mathrm{Me}_{4}$ rings is $1.506(4) \AA$, and thus even longer than what is observed for the dication $7(1.484(7) \AA)$. It is worth noting that significantly shorter central $\mathrm{C}-\mathrm{C}$ bonds were observed for Tschitschibabin's hydrocarbon $(1.448(4) \AA)^{9}$ and for the nitrogen analogue $\left[\mathrm{Ph}_{2} \mathrm{~N}-\left(\mathrm{C}_{6} \mathrm{H}_{4}\right)_{2}-\mathrm{NPh}_{2}\right]^{2+}(1.448(4) \AA)^{10 \mathrm{c}}$ Based on these structural data, one would assume for $\mathbf{8}$ an open shell ground state with very strong diradical character.

The results of the solution-based analyses were in line with conclusions drawn from the structural data. The UV-Vis spectrum of dimer 8 was similar to what was observed for the monoradicals 4-6, indicating that a more extensive $\pi$-system had not formed (as expected for a biphenylene bridge with orthogonal ring systems). Compound $\mathbf{8}$ was found to be ESR active (THF, RT), and the spectrum of 8 resembled that of the monoradical 5 (Fig. 3). The derived $g$-factor values for $\mathbf{5}$ and $\mathbf{8}$ are 2.0039 and 2.0038 , respectively.

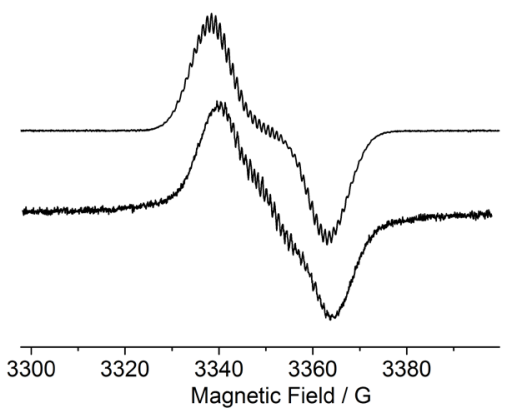

Figure 3. Stack-plot of the ESR spectra (THF, RT) acquired for 5 (top) and 8 (bottom). The ESR spectra were normalized with respect to the spectral amplitude and the microwave frequency.

Upon exposure to air, relatively quick decomposition was observed $\left(t_{1 / 2} \sim 80 \mathrm{~min}\right)$. The higher air sensitivity of $\mathbf{8}$, when compared to $\mathbf{4}$, is probably not due to the presence of two radical centers, but rather related to the fact that the aminyl radicals are adjacent to tetramethylbenzene groups. Due to steric interactions with the methyl substituents, the $\mathrm{N}_{2}$ unit is not coplanar with the adjacent arene ring (as observed for 4 ), and electron spin delocalization is less efficient. In fact, the air sensitivity of the monoradical $\mathbf{5}$, featuring likewise a tetramethylbenzene group, was similar to that of compound 8 (see SI, Figure S6 and S7).

A computational analysis of the electronic states of $\mathbf{8}$ was performed using (U)TPSS-(D3)/cc-pVDZ optimized geometries. The triplet and open-shell singlet biradical species were found to be isoenergetic and favored by almost $5 \mathrm{kcal} \mathrm{mol}^{-1}$ over the closedshell singlet specie (more details about these comparisons are provided in the supporting information). In addition, the charge-density difference between the $\alpha$ - and the $\beta$ - spin states, as depicted in Figure 2, essentially correspond to two times the spin of radical 4. These trends clearly indicate the absence of coupling between the two radical centers.

The description of $\mathbf{8}$ as a 'biradical' 14 with largely independent radical centers was confirmed by variable temperature ESR measurements (VT-ESR), which were performed for both the solid state and frozen liquid (THF solution) samples. Fitting the VT-ESR data to the Bleaney-Bowers equation confirmed that the singlet and triplet states are essentially isoenergetic with a negligible electron exchange interaction $J$.

To conclude: we have reported the synthesis and the characterization of a new class of aminyl radicals. Neutral monoradicals were obtained by reduction of azoimidazolium dyes featuring $\mathrm{N}$-aryl substituents at the heterocycle. Furthermore, we have shown that the reduction of a dimeric dye with an octamethylbiphenylene bridge between the azo groups results in the formation a biradical 
(8). Compound $\mathbf{8}$ is structurally related to compounds of the formula $\left[\mathrm{R}_{2} \mathrm{~N}-\left(\mathrm{C}_{6} \mathrm{H}_{2} \mathrm{R}^{\prime}{ }_{2}\right)_{2}-\mathrm{NR}_{2}\right]^{2+}$, which have received considerable attention in recent years. ${ }^{10} \mathrm{~A}$ unique feature of $\mathbf{8}$ is the fact that it has an overall charge of zero, as opposed to +2 , and that it can be described as a biradical ${ }^{14}$ despite the presence of a biphenylene bridge. In the absence of air, the monoradicals 4-6 and the biradical 8 display good stability in solution and in the solid state. The stability can be attributed to the steric shielding of the $\mathrm{N}$-aryl substituents, as well as to the stabilizing effect of the imidazolin-2-iminato group. Potential applications of these types of aminyl radicals include their utilization as electrochromic dyes, ${ }^{15}$ as polarizing agents in dynamic nuclear polarization, ${ }^{16}$ or as redox-active dyes in colorimetric assays. ${ }^{17}$

\section{ASSOCIATED CONTENT}

\section{Supporting Information}

Crystallographic data for 1', 4, 5, 7 and 8, as well as experimental procedures, spectral data, and computational details. This material is available free of charge via the Internet at http://pubs.acs.org.

\section{AUTHOR INFORMATION}

\section{Corresponding Author}

*kay.severin@epfl.ch.

\section{Notes}

The authors declare no competing financial interests.

\section{ACKNOWLEDGMENT}

The work was supported by the Swiss National Science Foundation and by the EPFL. We thank Carlos G. Morales-Guio for help with the CV measurements, Dr. Christophe Roussel for useful discussions, and Giacomo Cecot for help with the X-ray analyses.

\section{REFERENCES}

(1) Raue, R., Methine Dyes and Pigments. Ullman's Encyclopedia of Industrial Chemistry, 2000, pp. 1-55.

(2). (a) Yamada, S. (Fuji Photo Film Co., LTD), US 20070015912 A1, 2007; (b) Yamada, S. (Fuji Photo Film Co., LTD), JP 2006176745, 2006; (c) Yamada, S. (Fuji Photo Film Co., LTD), JP 2006169493, 2006; (d) Yamada, S. (Fuji Photo Film Co., LTD), JP 2006274054, 2006; (e) Yamada, S. (Fuji Photo Film Co., LTD), JP 2006328257, 2006

(3) Tskhovrebov, A. G.; Naested, L. C. E.; Solari, E.; Scopelliti, R.; Severin. K. Angew. Chem. Int. Ed. 2015, 54, 1289-1292.

(4) (a) Yoshida, T.; Monji, T.; Kawamori, D.; Akai, N.; Shibuya, K.; Kawai, A.; Chem. Lett. 2013, 1490-1492; (b) Ida, A.; Cohen, B.; Asaka, T.; Kawai, A.; Organero, J. A.; Shibuya, K.; Douhal, A. Phys. Chem. Chem. Phys. 2011, 13, 20318-20325; (c) Asaka, T.; Akai, N.; Kawai, A.; Shibuya, K. J. Photochem. Photobiol. A 2010, 209, 12-18; (d) Kawai, A.; Kawamori, D.; Monji, T.; Asaka, T.; Akai, N.; Shibuya, K. Chem. Lett. 2010, 39, 230-231.
(5) (a) Nyrkova, I.; Moulin, E.; Armao IV, J. J.; Maaloum, M.; Heinrich, B.; Rawiso, M.; Niess, F.; Cid, J.-J.; Jouault, N.; Buhler, E.; Semenov, A. N.; Giuseppone, N. ACS Nano 2014, 8, 10111-10124; (b) Faramarzi, V.; Niess, F.; Moulin, E.; Maaloum, M.; Dayen, J.-F.; Beaufrand, J.-B.; Zanettini, S.; Doudin, B.; Giuseppone, N. Nature Chem. 2012, 4, 485-490; (c) Moulin, E.; Niess, F.; Maaloum, M.; Buhler, E.; Nyrkova, I.; Giuseppone, N. Angew. Chem. Int. Ed. 2010, 49, 6974-6978.

(6) For compounds with a phosphinyl radical next to an imidazolidin-2iminato group see: Back, O.; Donnadieu, B.; von Hopffgarten, M.; Klein, S.; Tonner, R.; Frenkin, G.; Bertrand, G. Chem. Sci. 2011, 2, 858-861.

(7) (a) Gryn'ova, G.; Coote, M. L.; Corminboeuf, C. WIREs Comput. Mol. Sci. 2015, 5, 440-459; (b) Zeng, Z.; Shi, X.; Chi, C.; Navarrete, J. T. L.; Casado, J.; Wu, J. Chem. Soc. Rev. 2015, 44, 6578-6596; (c) Kubo, T. Chem. Rec. 2015, 15, 218-232; (d) Sun, Z.; Zeng, Z.; Wu, J. Acc. Chem. Res. 2014, 47, 2582-2591; (e) Sun, Z.; Zeng, Z.; Wu, J. Chem. Asian J. 2013, 8, 2894-2904; (f) Abe, M. Chem. Rev. 2013, 113, 7011-7088; (g) Sun, Z.; Ye, Q.; Chi, C.; Wu, J. Chem. Soc. Rev. 2012, 41, 7857-7889.

(8) Tschitschibabin, A. E. Chem. Ber. 1907, 40, 1810-1819.

(9) Montgomery, L. K.; Huffman, J. C.; Jurczak, E. A.; Grendze, M. P. J. Am. Chem. Soc. 1986, 108, 6004-6011, and refs cited.

(10) (a) Kurata, R.; Tanaka, K.; Ito, A. J. Org. Chem. 2016, 81, 137-145; (b) Wang, X.; Zhang, Z.; Song, Y.; Su, Y.; Wang, X. Chem. Commun. 2015, 51, 11822-11825; (c) Su, Y.; Wang, X.; Zheng, X.; Zhang, Z.; Song, Y.; Sui, Y.; Li, Y.; Wang, X. Angew. Chem. Int. Ed. 2014, 53, 2857-2861; (d) Zheng, X.; Wang, X.; Qiu, Y.; Li, Y.; Zhou, C.; Sui, Y.; Li, Y.; Ma, J.; Wang, X. J. Am. Chem. Soc. 2013, 135, 14912-14915; (e) Kamada, K. Fuku-en, S.-i.; Minamide, S.; Ohta, K.; Kishi, R.; Nakano, M.; Mutsuzaki, H.; Okamoto, H.; Higashikawa, H.; Inoue, K.; Kojima, S.; Yamamoto, Y. J. Am. Chem. Soc. 2013, 135, 232-241.

(11) (a) Tskhovrebov, A. G.; Vuichoud, B.; Solari, E.; Scopelliti, R. Severin, K. J. Am. Chem. Soc. 2013, 135, 9468-9492; (b) Tskhovrebov, A. G.; Solari, E.; Wodrich, M. D.; Scopelliti, R.; Severin, K. Angew. Chem. Int. Ed. 2012, 51, 232-234.

(12) (a) Lim, Z.; Zheng, B.; Huang, K.-W., Liu, Y., Wu. J. Chem. Eur J. 2015, 21, 18724-18729; (b) Rebmann, A.; Zhou, J.; Schuler, P.; Riekr, A.; Stegmann, H. B. J. Chem. Soc., Perkin Trans. 2 1997, 1615-1617.

(13) Zheng, S.; Barlow, S.; Risko, C.; Kinnibrugh, T. L.; Khrustalev, V. N.; Jones, S. C.; Antipin, M. Y.; Tucker, N. M.; Timofeeva, T. V.; Coropceanu, V.; Brédas, J.-L., Marder, S. R. J. Am. Chem. Soc. 2006, 128 , $1812-1817$

(14) According to IUPAC, 'biradical' is the term for molecules in which the two unpaired electrons act independently or nearly independently. For a more detailed discussion see ref. $7 \mathrm{f}$.

(15) Mortimer, R. J.; Dyer, A. L.; Reynolds, J. R. Displays 2006, 27, 2-18.

(16) (a) Muñoz-Gómez, J.-L.; Marín-Montesinos, I.; Lloveras, V.; Pons, M.; Vidal-Gancedo, J.; Veciana, J. Org. Lett. 2014, 16, 5402-5405; (b) Zagdoun, A.; Casano, G.; Ouari, O.; Schwarzwälder, M.; Rossini, A. J.; Aussenac, F.; Yulikov, M.; Jeschke, G.; Copéret, C.; Lesage, A.; Tordo, P.; Emsley, L. J. Am. Chem. Soc. 2013, 135, 12790-12797; (c) Dane, E. L.; Corzilius, B.; Rizzato, E.; Stocker, P.; Maly, T.; Smith, A. A.; Griffin, R. G.; Ouari, O.; Tordo, P, Swager, T. M. J. Org. Chem. 2012, 77, 1789-1797; (d) Matsuki, Y.; Maly, T.; Ouari, O.; Karoui, H.; Le Moigne, F.; Rizzato, E.; Lyubenova, S.; Herzfeld, J.; Prisner, T.; Tordo, P.; Griffin, R. G. Angew. Chem. Int. Ed. 2009, 48, 4996-500o.

(17) Huang, D.; Ou, B.; Prior, R. L. J. Agric. Food Chem. 2005, 53, 1841-1856. 
SYNOPSIS TOC

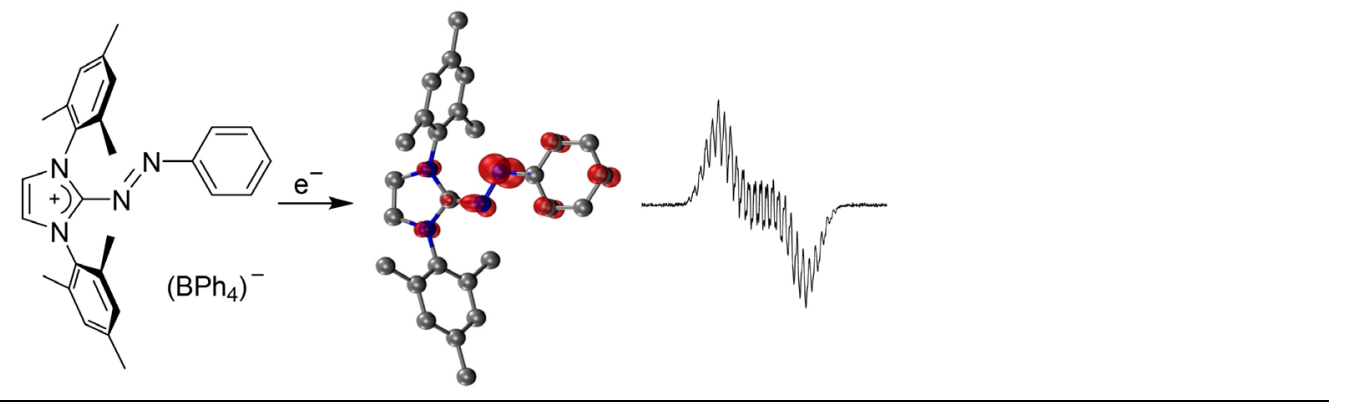

